\title{
Keratoconus: early onset, the worst prognosis, eye rubbing and hand-dominance
}

\begin{abstract}
Purpose: Keratoconus is an ectatic disorder of cornea and mostly involve teen aged group, still the pathogenesis and aetiology is not clearly defined. We try to establish the progression of the diseases is inversely proportional to the age of onset of the patient.

Design: It was an observational study, carried out at a private eye hospital where patient was referred for RGP contact lenses.

Methods: This observational study was carried out from Jan' 2017 to Dec' 2019 total three year period and 304 patients with Keratoconus were in the initial study and we divided them into two groups. Group: A, $\leq 25$ years old and Group: B, $>25$ years old but among these 304 patient we included 200 patients in our study those who completed minimum 3 years follow-up and meet the inclusion criteria.

Results: After three years ' $\mathrm{K}$ ' value in group: $\mathrm{A},<0.0001$ in group: $\mathrm{B},<0.3655$. Sim K's Astigmatism $<0.0001$ in group: A. $<0.0223$ in group: B. Central corneal thickness $<0.0001$ in group: A and 0.1957 in group: B. ' $\mathrm{K}$ ' value and central corneal thickness (CCT) deteriorate more in group: $\mathrm{A}$, than group: $\mathrm{B}$. It is also found that $\mathrm{KC}$ progress more in case of $\mathrm{VKC}$ and it is more prominent in dominant hand side.

Conclusion: At diagnosis, keratoconus is often more advanced in children than in adults, with faster disease progression. Early detection and close monitoring are therefore crucial in young patients.
\end{abstract}

Keyword: keratoconus, VKC, Sim K's astigmatism, central corneal thickness (CCT), hand dominance
Volume 10 Issue 4 - 2020

\author{
Anisur Rahman,' Sharah Rahman, ${ }^{2}$ Jamsed \\ Faridi, ${ }^{3}$ Abdus Salam, ${ }^{4}$ Tarzia Asma Zafrullah, ${ }^{5}$ \\ Saki sadia ${ }^{6}$ \\ 'Professor \& Head of the Ophthalmology department, Dhaka \\ Medical College, Bangladesh \\ ${ }^{2}$ Consultant Ophthalmologist, Bangladesh Eye Care Hospital, \\ Bangladesh \\ ${ }^{3}$ Registrar, department of Ophthalmology, Dhaka Medical \\ College, Bangladesh \\ ${ }^{4}$ Assistant professor, Sheikh Hasina Medical College, Jamalpur \\ ${ }^{5}$ Registrat \& Junior Ophthalmologist, Ispahani Islamia Eye \\ Institute and Hospital, Bangladesh \\ ${ }^{6}$ Assistant Registrar, Ophthalmology, National Institute of \\ Ophthalmology \& Hospital, Bangladesh
}

Correspondence: Anisur Rahman, Professor\& Head of the Ophthalmology department, Dhaka Medical College, Bangladesh, Tel +880-17l I-832397, Email anjumk8dmc@gmail.com

Received: April 0I, 2020 | Published: August 26, 2020

\section{Introduction}

The word keratoconus comes from the Greek words: Kerato (Cornea), and Conos (cone).$^{1}$ Keratoconus is a bilateral asymmetric non-inflammatory ectatic disease of the cornea. ${ }^{2}$ It is one of the devastating diseases of the cornea. Among the other ectatic diseases such as keratoglobus, pellucid marginal degeneration and posterior keratoconus, keratoconus is the most common. ${ }^{3,4}$ The thinning of the keratoconus is more prominent at the apex with the thinning there develops increasing degree of irregular astigmatism which can't be corrected by spectacles due to there is no "form" image. ${ }^{5}$ It is said that in keratoconus quality of vision is compromised than quantity of vision. Due to high irregularity of cornea patient sometimes correct his/her vision by squeezing the eye. Blurred vision is accompanies with halo at night and streaking of light sometimes "ghost" vision is at there,${ }^{6}$ it is due to higher order aberration, Keratoconus usually detected in teenage or 20's it can also start in childhood. ${ }^{5}$ According to Charles McGhee, ${ }^{7}$ in New Zealand .keratoconus is starts in kids usually at 12 years and they are very aggressive. But how long the disease will progress? Nobody knows but usually it ceases at 30 to 40 years. According to Rabinowitz ${ }^{2} \mathrm{KC}$ most commonly affects children. It is often detected at puberty and is progressive until the third to fourth decade of life, when it usually arrests. The prevalence of keratoconus varies from country to country and also races, it is between 1 in 500 and 1 in 2.000 individuals in the general population and the estimated prevalence is reported to be 54.5 per $100.000 .{ }^{8} 0.3$ Per 100.000 in Russia ${ }^{9}$ to 2.300 per 100.000 in Central India ${ }^{10}$ and 54.5 per 100.000 in the United States. ${ }^{11}$
Ethnicity is a major issue in keratoconus. There were two surveys in UK and it shows people from subcontinent (India, Pakistan and India) 4.4 to 7.5 times more sufferer compared with white Caucasians. ${ }^{3,12}$ It is supposed that ultraviolet light plays a role in keratoconus and geographical location plays an important role India, Middle East and New Zealand among the Kiwi has higher prevalence than location with cooler climates and less sunshine such as Finland, Denmark, Minnesota and Russia has less prevalence. ${ }^{13}$ Gender prevalence of keratoconus is still unclear but most of the studies show it is male predominant. ${ }^{12,14,15}$ Two studies from North India ${ }^{16,17}$ and one from Western India ${ }^{18}$ shows it is male predominant. Only one study from Central India shows $\mathrm{KC}$ is predominant in female ${ }^{10}$

Aetiology of $\mathrm{KC}$ is still poorly understood ${ }^{19}$ Lots of theories and hypotheses suggested about $\mathrm{KC}$ such as genetic, metabolic, immunological, endocrinological, ecological, etc. Ultraviolet ray has negative effect so it more common in hot climate. Dr. McGhee recommended "In some countries in the Middle East, keratoconus is very common because of consanguinity, so the genetic element prevails" Most patients do not have a family history, with only about $10 \%$ of offspring developing $\mathrm{KC}$; autosomal dominant transmission with incomplete penetrance ${ }^{20}$ The Collaborative Longitudinal Evaluation of Keratoconus Study does not show any association of $\mathrm{KC}$ and hormonal influences. ${ }^{21}$ Rather, $\mathrm{KC}$ is more prevalent in eye rubbing $^{22,23}$ According to NKCF (National Keratoconus Foundation) "Whether eye rubbing is the primary cause that results in structural changes to the cornea, or whether it is a contributory factor that makes an already vulnerable cornea weaker, it is certainly an activity that $\mathrm{KC}$ patients should avoid". ${ }^{24}$ We know most of the time $\mathrm{KC}$ is a bilateral 
but asymmetric diseases and hand-dominance is a major factor for the progression of the disease due to pressure effect on the eye.

\section{Methods}

It was a prospective longitudinal study done at Green Eye Hospital, Dhaka, Bangladesh. The study was initially conducted on 304 patients during the period of Jan 2017 to Dec 2018, total three year. Sample was collected purposefully and not all the patients were included in the study. This is the only RGP (Rigid Gas Permeable) contact lens center in Bangladesh in private level, so most of the diagnosed Keratoconus patients were referred to this center for trial, fitting and supply of RGP contact lenses. So, before trial of contact lens all the patients were advice for corneal topography and followup topography was done every year. Three year follow was recorded in the study. At the time of entry in our study there were 185 patients were $\leq 25$ year old and 119 were $>25$ year old. Among the 304 patients not all continue follow up for three years period so we took 100 patients from each group and total 200 patients were included in the study. In spite of corneal topography, patients were asked for allergic eye diseases and associated and other allergic disorder. Patients were asked for their eye rubbing habit. It is said that Keratoconus has a special character of eye rubbing, they rub their eye by the knuckle of the hand with a maximum pressure and it continues for 5 to 10 minutes, which is not seen in non Keratoconus patient. Rubbing habit was scored from 1 to 10 scales according to the severity of rubbing. In this case children usually don't give correct history so we rely on their parents or guardian. Keratoconus is a disease of teen age but many patients complain it started after the age of 19 years. In our study, we try to found the progression of the disease. Is there any gender, race or age predilection for the progression of Keratoconus? In our study age range was 6 years to 53 years and we divided them into two groups. Group: A $\leq 25$ years and group: B, $>25$ years, Group. Mean age of group: A 16.06 \pm 4.46 , and group: B 37.28 \pm 8.92 . Most of the patients were refer for RGP contact lenses (Because Green Eye Hospital is the only hospital that providing RGP/HARD lens since 1982). During the 80 decade RGP contact lens was not available in Bangladesh. Since 90 decade RGP lens came into market and now hard lens is obsolete from the market.

All the RGP contact lens does not give same comfort. It depends upon the Dk (diffusion co-efficient) and center thickness of the lens. ${ }^{25}$ Keratoconus was diagnosed by following signs ${ }^{26}$ all the signs were not present in a patient and final diagnosis and grading of $\mathrm{KC}$ was detected by corneal topography

a. Scissor reflex in retinoscopy

b. Oil droplet in ophthalmoscopy

c. Prominent corneal nerve in slit lamp biomicroscopy

d. Fleischer rings are pigmented rings in the peripheral cornea, resulting from iron deposition in basal epithelial cells, it is best seen in cobalt blue filter in slit lamp biomicroscopy

e. Vogt's striae, fine, roughly vertically parallel striations in the stroma.

f. Rizutti's sign or a conical reflection on nasal cornea when a penlight is shone from the temporal side

g. Munson's sign, a protrusion of the lower eyelid in downgaze.

h. Keratoconus is graded as mild, moderate and severe according to the highest axis of corneal power on Keratometry when it is less than $48 \mathrm{D}$ is mild, 48D -54D is moderate and more than $54 \mathrm{D}$ is severe ${ }^{20}$

We detect the progression of the diseases with the help of corneal topography. Several metrics can be used to monitor KC progression. Topographic indices such as ${ }^{27}$

1) mean keratometry,

2) simulated keratometry astigmatism, (maximum $\mathrm{K}$ - minimum $\mathrm{K})$

3) Value of the central corneal thickness (CCT) can be used.

4) Cut-off values of variables (K value .47.2 D, AST . 1.5 D. CCT: $450 \mu \mathrm{m})$

In our study, we included all the patients suffering from $\mathrm{KC}$ and it was diagnosed by topography. But the patient who has history of any ocular surgery, history of corneal ulcer (due to other cause) corneal scar not due to $\mathrm{KC}$ was excluded from study. $\mathrm{KC}$ is a bilateral but asymmetric disease, in our study we use the topographic data of the worst eye, hand dominance and eye rubbing habit was also recorded to see is there any association of eye rubbing and $\mathrm{KC}$ ? Most of the patients were right-handed and it is interesting to see that those have the history of vigorous eye rubbing their mostly right eye is affected more than the left eye..$^{28}$ And where no history of rubbing is there, severity is equivocal.

\section{Discussion}

During the study period of three year there were 304 patients came to us with Keratoconus and 185 were $\leq 25$ - year-old (Group: A) and rest 119 were $>25$-year-old (Group: B). Mean age in group: A was $15.09 \pm 4.87$ and group: B was $36.47 \pm 9.06 . \mathrm{KC}$ is mostly a male predominant disease and our study shows male, female ratio is $1.27: 1$ in total 304 patients. Due to loss of follow-up and didn't not meet the inclusion criteria there were 100 patients in each group. Mean age of group: A, was $16.06 \pm 4.46$ and group: B was $37.28 \pm 8.92$. Male female ratio was $1.35: 1$ in total 200 patients.

Figure 1 shows age and rubbing of the eye (X: age, Y: rubbing) is inversely proportional and table 2 shows rubbing habit and hand dominance of patient. Rubbing habit was scored from 1 to 10 scales according to severity of rubbing and it shows rubbing is inversely proportional to age. Among 200 patients, history of vigorous rubbing on 125 patients, in these 125 patients 17 was left handed and progression of $\mathrm{KC}$ was more in dominant hand at presentation and also at follow up ( $\mathrm{P}$ value $\leq 0.0034)$. In another non-rubbing group, 74 were right handed and 11 left handed and $p$ value was 0.28 which is statistically insignificant. So when there is no history of rubbing $\mathrm{KC}$ involvement of eye is equivocal. The commonly proposed pathogenesis is rubbing causes epithelial trauma and which increases the release of inflammatory mediators which may alter the corneal collagen and lead to corneal ectasia. ${ }^{29}$

From Table 3 mean $\mathrm{K}$ value at the time of diagnosis between two groups were $52.8 \pm 3.4$ and $52.3 \pm 3$.6. Two-tailed unpaired " $\mathrm{t}$ " test $\mathrm{p}$ value shows $<0.3839$, which is statistically insignificant but in group A after three years paired "t" test shows $p$ value is $<0.0001$ which is highly significant, on the other-hand in group $\mathrm{B}$ after three years paired "t" test shows $\mathrm{p}$ value is $<0.365$ which is statistically insignificant. When we compare the two groups after three years unpaired " $t$ " test shows $\mathrm{p}$ value is $<0.0001$ which is also statistically highly significant. 


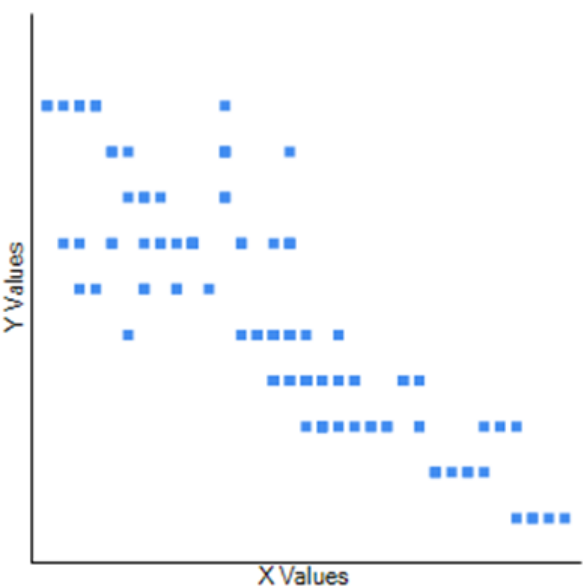

The value of $R$ is -0.86 .

This is a strong negative

correlation, which means that

high $\mathrm{X}$ variable scores go with

low Y variable scores. The P-

Value is $<.00001$. The result is

significant at $\mathrm{p}<.05$

Figure I Shows age and rubbing of the eye (X: age,Y: rubbing) is inversely proportional.

Table I Demographic profile

\begin{tabular}{llc}
\hline \multicolumn{3}{l}{ Demographic profile of $\mathbf{3 0 4}$ patients at first visit } \\
\hline & Group:A, $\leq 25$ year $(n=\mid 85)$ & Group: $B .>25$ year $(n=\mid 19)$ \\
Age & $\mid 5.09 \pm 4.87$ & $36.47 \pm 9.06$ \\
Gender $\quad$ Male $=10 \mid$ & Male $=69$ \\
& Female $=84$ & Female $=50$ \\
Demographic profile of 200 patients at last visit & \\
Age & I6.06 \pm 4.46 & $37.28 \pm 8.92$. \\
Gender $\quad$ Male $=57$ & Male $=58$ \\
& Female $=43$ & Female $=42$
\end{tabular}

Table 2 Hand dominance

\begin{tabular}{llllll}
\hline & Right handed & Left handed & Total & Expected & \\
\hline KC more & 88 & 12 & 100 & 84.67 & \\
KC less & 20 & 5 & 25 & 40.33 & Two-tailed P value equals 0.0034 \\
Total & 108 & 17 & 125 & 125 &
\end{tabular}

Among 200 patients, history of vigorous rubbing on 125 patients, in these 125 patients 17 was left handed and progression of KC was more in dominant hand at presentation and also at follow up.

Table 3 Mean $\mathrm{K}$ value between the two groups

\begin{tabular}{|c|c|c|}
\hline \multicolumn{3}{|c|}{ Mean $K$ value at presentation between Group: A \& B } \\
\hline Group: A \& B & Mean \pm SD & $P$ value \\
\hline \multirow[t]{2}{*}{ Group: $A \leq 25(n=100)$} & $52.8 \pm 3.4$ & \\
\hline & & $<0.3839 \mathrm{NS}$ \\
\hline Group: $B>25(n=100)$ & $52.3 \pm 3.6$ & Unpaired $\mathrm{t}$ test \\
\hline \multicolumn{3}{|c|}{ Difference of Mean K value during follow-up period in Group :A } \\
\hline Group:A & Mean $\pm S D$ & $P$ value \\
\hline Mean $\mathrm{K}$ at the time of diagnosis & $52.8 \pm 3.4$ & $<0.000$ IS \\
\hline Mean $\mathrm{K}$ three years after diagnosis & $55.4 \pm 3.2$ & Paired $t$ test \\
\hline Difference of Mean $\mathrm{K}$ value durin & up period in & \\
\hline
\end{tabular}


Table Continued...

\begin{tabular}{lcl}
\hline \multicolumn{3}{c}{ Mean K value at presentation between Group:A \& B } \\
\hline Group: B & Mean \pm SD & PValue \\
Mean K at the time of diagnosis & $52.4 \pm 3.2$ & $<0.3655 \mathrm{NS}$ \\
Mean K three years after diagnosis & $52.9 \pm 3.6$ & Paired t test \\
Mean K value after 3-year between Group:A \& B & \\
Group:A $\leq 25(n=100)$ & $55.4 \pm 3.2$ & $<0.000$ IS \\
Group: B $>25(n=100)$ & $52.9 \pm 3.6$ & Unpaired t test \\
\hline
\end{tabular}

NS, non-significant; S: significant

From Table 4 Sim K's astigmatism at presentation between Group: A \& B is $5.49 \pm 1.55$ and $5.26 \pm 1.39$, unpaired "t" test shows $\mathrm{p}$ value 0.257 which is statistically insignificant but in group A after three years paired " $t$ " test shows $p$ value is $<0.0001$ which is highly significant, on the other-hand in group B after three years paired " $\mathrm{t}$ " test shows $p$ value is $<0.223$ which is statistically insignificant. When we compare the two groups after three years unpaired " $t$ " test shows $p$ value is $<0.0001$ which is also statistically highly significant.

From Table 5 Central corneal thickness $(3 \mathrm{~mm})$ at presentation between Group: A \& B is $402.39 \pm 41.40$ and $404.08 \pm 40.32$, unpaired " $\mathrm{t}$ " test shows $\mathrm{p}$ value 0.7703 which is statistically insignificant but in group A after three years paired "t" test shows p value is $<0.0001$ which is highly significant, on the other-hand in group B after three years paired "t" test shows $\mathrm{p}$ value is $<0.1957$ which is statistically insignificant. When we compare the two groups after three years unpaired " $\mathrm{t}$ " test shows $\mathrm{p}$ value is $<0.0003$ which is also statistically highly significant. ${ }^{30-32}$ From table 3,4 and 5 it is seen that all the parameters of $\mathrm{KC}$ deteriorate in case of early start of $\mathrm{KC}$, but it is usually static in case of late onset. We know that VKC is one of the associations of $\mathrm{KC}^{33,34}$ and $\mathrm{VKC}$ is a disease of teen age so vigorous rubbing accelerate the disease process and it is more prominent in dominant hand side due to pressure effects on cornea is more on the right eye in right handed person and more on the left eye in case of left handed person.

Table 4 Sim K's Astigmatism (Central 3mm zone)

\begin{tabular}{|c|c|c|}
\hline \multicolumn{3}{|l|}{ Sim K's astigmatism at presentation between Group: A \& B } \\
\hline Group:A \& B & Mean $\pm S D$ & $P$ value \\
\hline Group: $A \leq 25(n=100)$ & $5.49 \pm 1.55$ & \multirow{2}{*}{0.2577 NS unaired $t$ test } \\
\hline Group: $B>25(n=100)$ & $5.26 \pm 1.39$ & \\
\hline \multicolumn{3}{|c|}{ Difference of Sim K's Astigmatism during follow-up period in Group :A } \\
\hline Group:A & Mean $\pm S D$ & $P$ value \\
\hline Mean $\mathrm{K}$ at the time of diagnosis & $5.49 \pm 1.55$ & \multirow{2}{*}{$<0.000$ IS Paired $\mathrm{t}$ test } \\
\hline Mean $\mathrm{K}$ three years after diagnosis. & $6.98 \pm 1.69$ & \\
\hline \multicolumn{3}{|c|}{ Difference of Sim K's Astigmatism during follow-up period in Group : B } \\
\hline Group: B & Mean \pm SD & PValue \\
\hline Mean $\mathrm{K}$ at the time of diagnosis & $5.26 \pm 1.39$ & \multirow{2}{*}{$<0.0223$ S Paired $t$ test } \\
\hline Mean $\mathrm{K}$ three years after diagnosis & $5.37 \pm 1.64$ & \\
\hline \multicolumn{3}{|c|}{ Difference of Sim K's astigmatism after three-year between Group:A \& B } \\
\hline Mean $\mathrm{K}$ minimum three years after diagnosis in group: $\mathrm{A}$ & $6.98 \pm 1.69$ & \multirow{2}{*}{$P$ value paired $t$ test (two tailed) $<0.000 \mathrm{I}$} \\
\hline Mean $\mathrm{K}$ three years after diagnosis in group: $\mathrm{B}$ & $5.37 \pm 1.64$ & \\
\hline
\end{tabular}

NS, non-significant; S, significant

Table 5 Changes of Central corneal thickness

\begin{tabular}{llll}
\hline \multicolumn{3}{c}{ CCT at presentation between Group:A \& B } \\
\hline Group: A \& B & Mean \pm SD & PValue \\
Group: A $(n=100)$ & $402.39 \pm 41.40$ & \\
Group: B $(n=100)$ & $404.08 \pm 40.32$ & 0.7703 NS Unpaired t test \\
\hline
\end{tabular}


Table Continued.

Difference of CCT during follow-up period in Group :A

Group: A
At the time of diagnosis
Minimum after three years
\[ \text { Difference of CCT during follow-up period in Group :B } \]
Group: B
At the time of diagnosis
Minimum after three years
CCT between Group:A \& B after three years of follow-up
After three years in group: A
After three years in group: B

Mean \pm SD $\quad P$ value

$402.39 \pm 41.4$

$38 I .4 I \pm 40.93$

$\leq 0.000$ IS Paired t test

Mean $\pm S D$

$404.08 \pm 40.32$

PValue0.1957NS

$403.36 \pm 43.06$

$381.4 I \pm 40.93$

$403.36 \pm 43.06$

The two-tailed $\mathrm{P}$ value equals 0.0003

NS, non-significant; $S$, significant

\section{Conclusion}

Keratoconus is a nightmare for a patient as well as an ophthalmologist. The pathogenesis is still not clear so many hypothesis has arises hereditary, ethnicity, climate, geographical location, rubbing eye is supposed to be responsible for $\mathrm{KC}$ but irrespective of all, micro trauma of corneal epithelium by rubbing eye is one of the most common pathogenesis of $\mathrm{KC}$. And $\mathrm{VKC}$ is the diseases of teen age and progression of $\mathrm{KC}$ is more in teen than adult age group. The present study demonstrates a clear inverse correlation between age and severity of keratoconus.

\section{Limitation of the study}

The main limitation of the study it was a single center study and private hospital so it didn't cover the patient of low-socioeconomic group. Drop out of the patient was about $34 \%$ it was one of the weakness of the study.

\section{Acknowledgments}

None.

\section{Funding}

None.

\section{Conflicts of interest}

Authors declare that there is no conflict of interest.

\section{References}

1. Khor Omer. Epidemiology of Keratoconus Worldwide. The open Ophthalmology journal Year. 2018;12:289-299.

2. Rabinowitz YS. Keratoconus. Surv Ophthalmol. 1998;42(4):297-319.

3. Krachmer JH, Feder RS, Belin MW. Keratoconus and related noninflammatory corneal thinning disorders. Surv Ophthalmol. 1984;28(4):293-322.

4. Fournié P, Touboul D, Arné JL, et al. Keratoconus. J Fr Ophtalmol. 2013;36(7):618-626.

5. Keratoconus. Cleveland Clinic. 2019.
6. 5 Fast Facts about Keratoconus. Duke University Health System. 2014.

7. Charles McGhee. New treatment options revise the prognosis for keratoconus. Ophthalmology Times. 2015.

8. Khaled K Abu-Amero, Abdulrahman M Al-Muammar, Altaf A Kondkar. Genetics of Keratoconus: Where Do We Stand? Journal of Ophthalmology. 2014

9. Gorskova EN, Sevost'ianov EN. Epidemiology of keratoconus in the Urals. Vestn Oftalmol. 1998;114:38-40.

10. Jonas JB, Nangia V, Matin A, Kulkarni M, Bhojwani K. Prevalence and associations of keratoconus in rural Maharashtra in central India: The central India Eye Medical Study. Am J Ophthalmol. 2009;148:760-765.

11. Kennedy RH, Bourne WM, Dyer JA. A 48-year clinical and epidemiologic study of keratoconus. Am J Ophthalmol. 1986;101(3):267-273.

12. Pearson AR, Soneji B, Sarvananthan N, et al. Does ethnic origin influence the incidence or severity of keratoconus? Eye. 2000;14:625-628.

13. Nikhil S Gokhale. Epidemiology of keratoconus. Indian J Ophthalmol. 2013;61(8):382-383.

14. Owens H, Gamble G. A profile of keratoconus in New Zealand. Cornea. 2003;22:122-125

15. Wagner H, Barr JT, Zadnik K. Collaborative longitudinal evaluation of keratoconus (CLEK) study: Methods and findings to date. Cont Lens Anterior Eye. 2007;30:223-232.

16. Fatima T, Acharya MC, Mathur U, et al. Demographic profile and visual rehabilitation of patients with keratoconus attending contact lens clinic at a tertiary eye care centre. Cont Lens Anterior Eye. 2010;33:19-22.

17. Sharma R, Titiyal JS, Prakash G, et al. Clinical profile and risk factors for keratoplasty and development of hydrops in north Indian patients with keratoconus. Cornea. 2009;28:367-370.

18. Agrawal VB. Characteristics of Keratoconus patients at a tertiary eye center in India. J Ophthalmic Vis Res. 2011;6:87-91.

19. AE Davidson, S Hayes, A J Hardcastle, et al. The pathogenesis of keratoconus. Eye. 2014;28(2):189-195.

20. Fink BA, Sinnott LT, Wagner H, et al. The influence of gender and hormone status on the severity and progression of keratoconus. Cornea. 2010;29(1):65-72. 
21. R J Harrison, PT Klouda, D L Easty, et al. Association between keratoconus and atopy. Br J Ophthalmol. 1989;73(10):816-822.

22. Uchechukwu L Osuagwu, Saud A Alanazi. Eye rubbing-induced changes in intraocular pressure and corneal thickness measured at five locations, in subjects with ocular allergy. Int J Ophthalmol. 2015;8(1):81-88.

23. NKCF. National Keratoconus Foundation. Eye Rubbing Cause of Keratoconus? 2019.

24. Brad Bowling. Kanski's clinical ophthalmology: A systematic approach 8th edition. Elsevier. 2016.

25. Contact Lens Practice, $3^{\text {rd }}$ ed. Elsevier BV. 2019.

26. Penny A Asbell, Theodora Petratos. Keratoconus. Eyewiki. 2019.

27. The keratoconus diary. Documentation of keratoconus progression.

28. Renato Ambrósio Jr. Don't Rub Your Eyes! 2019.
29. Sharma N, Rao K, Maharana PK, et al. Ocular allergy and keratoconus. Indian J Ophthalmol. 2013;61(8).

30. Millodot M, Ortenberg I, Yacouel, et al. Effect of ageing on keratoconic corneas. J Optom. 2016;9(2):72-77.

31. Ertan A, Muftuoglu O. Keratoconus clinical findings according to different age and gender groups. Cornea. 2008;27:1109-1113.

32. Zadnik K, Barr JT, Edrington TB. Baseline findings in the Collaborative Longitudinal valuation of Keratoconus (CLEK) Study. Invest Ophthalmol Vis Sci. 1998;39:2537-2546.

33. Cameron JA, AA Al-Rajhi, IA Badr. Corneal ectasia in vernal keratoconjunctivitis. Ophthalmology. 1989;96(11):1615-1623.

34. Courtney L Kraus. Vernal Keratoconjunctivitis. American Academy of Ophthalmology. 2019 